\title{
EXTREMAL PROPERTIES OF EULER-MACLAURIN AND GREGORY QUADRATURE FORMULAS
}

It is known that the modified Euler-Maclaurin quadrature formula is the best quadrature formula in the sense of A. Sard of certain form for the set $W^{r} L_{q}\left[{ }^{1-3}\right]$. We show that this formula is still optimal if variable nodes are allowed, and trapezoidal rule is the optimal formula for certain subset of $W^{r} L_{q}$. As a result, we obtain that the Gregory quadrature formula is asymptotically optimal for the set $W^{r} L_{q}$.

\section{Introduction}

Let us denote by $W^{r} L_{q}$ the set of all functions $f(x)$ with absolutely continuous derivatives $f^{(r-1)}(x)$ and satisfying condition $\left\|f^{(r)}(x)\right\|_{L q(0,1)} \leqslant 1$;

$$
\begin{gathered}
\widetilde{W}^{r} L_{q}=\left\{f(x): f(x) \in W^{r} L_{q}, \quad f^{(j)}(0)=f^{(j)}(1) \quad(j=0, \ldots, r-1)\right\} ; \\
\bar{W}^{r} L_{q}=\left\{f(x): f(x) \in W^{r} L_{q}, \quad f^{(2 j-1)}(0)=f^{(2 j-1)}(1) \quad(j=1, \ldots,[r / 2])\right\}
\end{gathered}
$$

$([\alpha]$ is the greatest integer $\leqslant \alpha)$.

The quadrature formula

$$
\int_{0}^{1} f(x) d x=\sum_{k=1}^{n} A_{k} f\left(x_{k}\right)+R_{n}(f)
$$

with nodes $x_{k}^{*}$ and coefficients $A_{k}^{*}(k=1, \ldots, n)$ is said to be the optimal [ $\left.{ }^{4}\right]$ quadrature formula (1) for the set $H$ of functions $f(x)$ if exact bound for the remainder of this formula

$$
R_{n}[H]=\sup _{f \in H}\left|R_{n}(f)\right|
$$

is minimized by these nodes and coefficients. We denote by $E_{n}[H]$ the exact bound for the remainder of the optimal formula (1) for the set $H$. We call formula (1) asymptotically optimal formula for the set $H$ if exact bound for the remainder of this formula satisfies condition

$$
\lim _{n \rightarrow \infty} \frac{E_{n}[H]}{R_{n}[H]}=1
$$

following $\left.{ }^{5}\right]$.

We denote by $T_{n}(f)$ the quadrature sum of trapezoidal rule

$$
T_{n}(f)=\frac{1}{n}\left(\frac{1}{2} f(0)+\sum_{k=1}^{n-1} f\left(\frac{k}{n}\right)+\frac{1}{2} f(1)\right) .
$$


The classical Euler-Maclaurin quadrature formula $[2,3,6,7]$ is

$$
\int_{0}^{1} f(x) d x=T_{n}(f)-\sum_{j=1}^{r-1} \frac{B_{j+1}}{(j+1) ! n^{j+1}}\left(f^{(j)}(1)-f^{(j)}(0)\right)+R(f),
$$

where $B_{j}$ 's are Bernoulli numbers. We consider modified Euler-Maclaurin formula

$$
\int_{0}^{1} f(x) d x=T_{n}(f)-\sum_{j=1}^{r-1} \frac{\bar{B}_{j+1}}{(j+1) ! n^{j+1}}\left(f^{(j)}(1)-f^{(j)}(0)\right)+R_{n+1}^{E}(f),
$$

where $\bar{B}_{j}=B_{j}(j=2, \ldots, r-1), \bar{B}_{r}=B_{r}-c_{r, p}$, and quantity $c_{r, p}$ is uniquely determined by condition

$$
\frac{1}{r !}\left\|B_{r}(x)-c_{r, p}\right\|_{L_{p}(0,1)}=\frac{1}{r !} \min _{c}\left\|B_{r}(x)-c\right\|_{L_{p}(0,1)}=B_{r, p},
$$

where $B_{r}(x)$ is Bernoulli polynomial, $p^{-1}+q^{-1}=1$. The formulas (3) were considered earlier in papers $\left[{ }^{1,3}\right]$. Note that $c_{r, p}=0$, when $p=2$ or $r$ is odd, so that in these cases formulas (2) and (3) coincide.

The Gregory formulas are principally constructed by substitution for the integrand's derivatives at the ends of the interval of integration by values in these points of derivatives of polynomials interpolating the integrand in certain integration nodes $\left[{ }^{6,7}\right]$. We call the Gregory formula the quadrature formula

$$
\int_{0}^{1} f(x) d x=T_{n}(f)-\sum_{j=1}^{r-1} \frac{\dot{\bar{B}}_{j+1}}{(j+1) ! n^{j+1}}\left(Q^{(j)}(1)-P^{(j)}(0)\right)+R_{n+1}^{G}(f),
$$

obtained in the same way from (3), where $P(x)$ and $Q(x)$ are polynomials of degree $m$ interpolating function $f(x)$ in points $0,1 / n, \ldots, m / n$ and $(n-m) / n,(n-m+1) / n, \ldots, 1$, respectively. Of course, for practical use it requires to substitute the values $Q^{(j)}(1)$ and $P^{(j)}(0)$ by differences $\nabla^{k} f(1)$ and $\triangle_{k} f(0)$, as it is done in $\left[{ }^{6,7}\right]$, but we need not do it for our purpose.

Subsequently we use the following result of V. P. Motorny $\left[{ }^{8}\right]$ and A. A. Zhensykbayev [ $\left.{ }^{9}\right]$.

$\mathrm{T}$ he or e $\mathrm{m}$. The rectangular formula

$$
\int_{0}^{1} f(x) d x=\frac{1}{n} \sum_{k=0}^{n-1} f\left(\frac{k}{n}\right)+R(f)
$$

is the optimal quadrature formula of the form

$$
\int_{0}^{1} f(x) d x=\sum_{k=0}^{n-1} A_{k} f\left(x_{k}\right)+R_{n}(f)
$$

with fixed node $x_{0}=0$ for the set $W^{r} L_{q}$. This formula has the remainder

where

$$
R_{n}(f)=\int_{0}^{1} f^{(r)}(t) K(t) d t,
$$

$$
K(t)=\frac{1}{n^{r} \cdot r !}\left[B_{r}^{*}(-n t)-c_{r, p}\right]
$$


and $B_{r}^{*}(x)$ is 1-periodic Bernoulli polynomial's extension. The exact bound for the remainder of this formula is

$$
R_{n}\left[\mathscr{W}^{r} L_{q}\right]=\frac{B_{r, p}}{n^{r}} \quad\left(\frac{1}{p}+\frac{1}{q}=1\right) .
$$

Remark 1. This theorem is stated for $q=1$ and even $r, q=\infty$ and arbitrary $r$ in $\left[{ }^{8}\right]$, and for $1<q<\infty$ and arbitrary $r$ in $\left[{ }^{9}\right]$. The case $q=1, r$ odd follows clearly from [ [ ${ }^{9}$ by $q \rightarrow 1$.

Corollary 1 . The inequality

$$
E_{n}\left[\mathscr{W}^{r} L_{q}\right] \geqslant E_{n}\left[\mathscr{W}^{r} L_{q}\right]=\frac{B_{r, p}}{n^{r}}
$$

is valid.

\section{Modified Euler-Maclaurin Formula and Trapezoidal Rule}

In this section we ascertain the optimality of modified Euler-Maclaurin quadrature formula (3) and trapezoidal rule. The proofs are based on theorem 1 and results of paper $\left[{ }^{10}\right]$ (see also theorem 2 in $\left[{ }^{11}\right]$ ).

Theorem 2. The modified Euler-Maclaurin formula (3) is the optimal formula among all formulas of the form

$$
\int_{0}^{1} f(x) d x=\sum_{k=0}^{n} A_{k} f\left(x_{k}\right)+\sum_{j=1}^{r-1} \alpha_{j}\left(f^{(j)}(1)-f^{(j)}(0)\right)+R_{n+1}(f)
$$

with fixed nodes $x_{0}=0, x_{n}=1$ for the set $W^{r} L_{q} \quad(1 \leqslant q \leqslant \infty)$. The exact bound for the remainder of this formula is equal to quantity (7).

$\mathrm{Proof}$. It follows from paper [10] that the nodes $x_{k}$, coefficients $B_{k}(k=0, \ldots, n-1)$ and exact bound for the remainder of the optimal formula of the form

$$
\int_{0}^{1} f(x) d x=\sum_{k=0}^{n-1} B_{k} f\left(x_{k}\right)+\sum_{j=0}^{r-1} \beta_{j}\left(f^{(j)}(1)-f^{(j)}(0)\right)+R_{n+1}(f)
$$

with fixed node $x_{0}=0$ for the set $W^{r} L_{q}$ coincide with those of optimal for the set $W^{r} L_{q}$ formula (5) obtained in theorem 1 . The evaluation of coefficients $\beta_{j}$ is also founded on paper [ $\left.{ }^{10}\right]$ and relation (7),

$$
\beta_{j}=(-1)^{j} K^{(r-j-1)}(1)=\frac{(-1)^{j-1}}{r ! n^{j+1}} B_{j+1}(0) \quad(j=0, \ldots, r-1)
$$

but we omit the computational details. Formulas (10) and (9) differ only in designations, therefore the theorem is established.

R e m a r k 2. The result of this theorem was conjectured by I. J. Schoenberg $\left[{ }^{2}\right]$ for $q=2$ and C. A. Micchelli $\left[{ }^{3}\right]$ for $1 \leqslant q \leqslant \infty$.

Th o o r m 3. The trapezoidal rule with exact bound for the remainder equal quantity (7) is the optimal formula among all formulas of the form

$$
\int_{0}^{1} f(x) d x=\sum_{k=0}^{n} A_{k} f\left(x_{k}\right)+R_{n+1}(f)
$$

with fixed nodes $x_{0}=0, x_{n}=1$ for the set $\bar{W}^{r} L_{q}(1 \leqslant q \leqslant \infty)$.

$\mathrm{P}$ roof. We obtain from equality

$$
\bar{B}_{j+1}=0 \quad(j=2,4, \ldots, 2[(r-1) / 2])
$$


and theorem 2 that the modified Euler-Maclaurin formula (3) with exact bound for the remainder (7) is the optimal formula among all formulas

$$
\int_{0}^{1} f(x) d x=\sum_{k=0}^{n} A_{k} f\left(x_{k}\right)+\sum_{j=1}^{[r / 2]} \gamma_{j}\left(f^{(2 j-1)}(1)-f^{(2 j-1)}(0)\right)+R(f)
$$

with fixed nodes $x_{0}=0, x_{n}=1$ for the set $W^{r} L_{q}$. The result of the theorem follows clearly from the above-said and paper [ $\left.{ }^{10}\right]$. even $r$.

Remark 3. This theorem was established in paper [ [11] for $q=2$ and

\section{Gregory Formulas}

In this section we estimate the exact bound for the remainder of Gregory quadrature formula (4) and show that this formula is asymptotically optimal for the set $W^{r} L_{q}$, if $m \geqslant r-1$. Our considerations are founded on the result of theorem 2 and inequality (8).

$\mathrm{T}$ h e o r m 4. The exact bound for the remainder of Gregory formula (4) satisfies inequality

$$
R_{n+1}^{G}\left[W^{r} L_{q}\right] \leqslant \frac{B_{r, p}}{n^{r}}+\frac{A}{n^{r+1 / p}} \quad\left(p^{-1}+q^{-1}=1\right),
$$

where quantity $A$ does not depend on $n$ when $m \geqslant r-1$.

Proof. Let us estimate the difference

$$
R_{n+1}^{G}(f)-R_{n+1}^{E}(f)=M_{1}(f)-M_{0}(f)
$$

of remainder functionals of formulas (3) and (4), where

$$
\begin{aligned}
& M_{0}(f)=\sum_{j=1}^{r-1} \frac{\bar{B}_{j+1}}{(j+1) ! n^{j+1}}\left(P^{(j)}(0)-f^{(j)}(0)\right), \\
& M_{1}(f)=\sum_{j=1}^{r-1} \frac{\bar{B}_{j+1}}{(j+1) ! n^{j+1}}\left(Q^{(j)}(1)-f^{(j)}(1)\right),
\end{aligned}
$$

for functions $f(x) \in W^{r} L_{q}$. We denote

$$
\begin{gathered}
\omega(x)=x(x-1) \ldots(x-m), \\
l_{h}(x)=\frac{\omega(x)}{\left(x-x_{k}\right) \omega^{\prime}\left(x_{k}\right)} \quad(k=0, \ldots, m) .
\end{gathered}
$$

The representation

$$
f(x)=\pi_{r-1}(x)+\frac{1}{(r-1) !} \int_{0}^{1}(x-t)_{+}^{r-1} f^{(r)}(t) d t
$$

is fulfilled for functions $f(x) \in W^{r} L_{q}$, where $\pi_{r-1}(x)$ is polynomial of degree $\leqslant r-1, u_{+}^{j}=u^{j}$ if $u \geqslant 0, u_{+}{ }^{j}=0$ if $u<0$, therefore polynomial interpolating $f(x)$ in nodes $0,1 / n, \ldots, m / n$ is

$$
P(x)=\pi_{r-1}(x)+\sum_{k=0}^{m} \frac{l_{k}(n x)}{(r-1) !} \int_{0}^{1}\left(\frac{k}{n}-t\right)_{+}^{r-1} f^{(r)}(t) d t .
$$

We obtain equality 


$$
M_{0}(f)=\sum_{j=1}^{r-1} \sum_{k=1}^{m} \frac{\bar{B}_{j+1} i_{k}^{(j)}(0)}{(j+1) !(r-1) ! n} \int_{0}^{1}\left(\frac{k}{n}-t\right)_{+}^{r-1} f^{(r)}(t) d t
$$

using (13)-(15). From this equality we obtain by Hölder's inequality the inequality

$$
\left|M_{0}(f)\right| \leqslant\left\|\sum_{j=1}^{r-1} \sum_{k=1}^{m} \frac{\bar{B}_{j+1} l_{k}^{(j)}(0)}{(j+1) !(r-1) ! n}\left(\frac{k}{n}-t\right)_{+}^{r-1}\right\|_{L_{p}(0,1)} .
$$

If $1 \leqslant p<\infty$, equality

$$
\begin{gathered}
\left\|\sum_{j=1}^{r-1} \sum_{k=1}^{m} \frac{\bar{B}_{j+1} l_{k}^{(j)}(0)}{(j+1) !(r-1) ! n}\left(\frac{k}{n}-t\right)_{+}^{r-1}\right\|_{L_{p}(0,1)}^{p}= \\
=\sum_{i=1}^{m} \int_{i-1}^{i / n}\left|\sum_{j=1}^{r-1} \sum_{k=i}^{m} \frac{\bar{B}_{j+1} l_{k}^{(j)}(0)}{(j+1) !(r-1) ! n}\left(\frac{k}{n}-t\right)^{r-1}\right|^{p} d t= \\
=\sum_{i=1}^{m} \int_{0}^{1}\left|\sum_{j=1}^{r-1} \sum_{k=i}^{m} \frac{\bar{B}_{j+1} l_{k}^{(j)}(0)}{(j+1) !(r-1) ! n^{r}}(k-i+t)^{r-1}\right|^{p} \frac{d t}{n}=\frac{A_{s}^{p}}{n^{r p+1}}
\end{gathered}
$$

is obtained by substitution of variable for the right side of (16), and quantity $A_{1}$ does not depend on $n$. Analogous remains valid for $p=\infty$, too. From here and (16) follows inequality

$$
\left|M_{0}(f)\right| \leqslant A_{1} / n^{r+1 / p}\left(f(x) \in W^{r} L_{q}\right) .
$$

The inequality

$$
\left|M_{1}(f)\right| \leqslant A_{1} / n^{r+1 / p}\left(f(x) \in W^{r} L_{q}\right)
$$

is established in the same way.

Then, from these inequalities and (12), it is easy to check that inequality

$$
\left|R_{n+1}^{G}(f)-R_{n+1}^{E}(f)\right| \leqslant\left|M_{0}(f)\right|+\left|M_{1}(f)\right| \leqslant A / n^{r+1 / p}
$$

is fulfilled for functions $f(x) \in W^{r} L_{q}$, where quantity $A$ does not depend on $n$. From here and theorem 2 we obtain inequality

$$
\left|R_{n+1}^{G}(f)\right| \leqslant\left|R_{n+1}^{E}(f)\right|+\left|R_{n+1}^{G}(f)-R_{n+1}^{E}(f)\right| \leqslant \frac{B_{\dot{r}_{l} p}}{n^{r}}+\frac{A}{n^{r+1 / p}} .
$$

Q.E.D.

Corollary 2. The exact bound for the remainder of the best formula (11) with fixed equidistant nodes $x_{k}=k / n(k=0, \ldots, n)$ for the set $W^{r} L_{q}\left[{ }^{12-15}\right]$ satisfies inequality

$$
R_{n+1}\left[W^{r} L_{q}\right] \leqslant \frac{B_{r, p}}{n^{r}}+\frac{A}{n^{r+1 / p}} .
$$

Theorem 5. The Gregory formula (4) is the asymptotically optimal formula (1) for the set $W^{r} L_{q}(1<q \leqslant \infty)$ if $m \geqslant r-1$.

Proof. The relation

$$
R_{n}^{G}\left[W^{r} L_{q}\right] \leqslant \frac{B_{r, p}}{(n-1)^{r}}+\frac{A}{(n-1)^{r+1 / p}}=\frac{B_{r, p}}{n^{r}}(1+o(1))
$$


is followed from theorem 4. From here and inequality (8) we obtain the statement of the theorem.

Corollary 3 . The relation

$$
E_{n}\left[W^{r} L_{q}\right]=\frac{B_{r, p}}{n^{r}}(1+o(1)) \quad(1<q \leqslant \infty)
$$

is valid.

Corollary 4. The best formula (9) with fixed equidistant nodes $x_{k}=k / n(k=0, \ldots, n)$ for the set $W^{r} L_{q}$ is asymptotically optimal formula (1) for this set if $1<q \leqslant \infty$.

\section{REFERENCES}

1. Бахвалов Н. С. Оптимальные свойства формул численного интегрировання Адамса и Грегори. - В кн.: Вопросы вычислительной математики и вычислительной техники. М., 1963, с. 9-26.

2. Schoenberg, I. J. Monosplines and quadrature formulae. - In: Theory and applications of spline functions. New York, 1969, p. 157-207.

3. Micchelli, C. A. Best quadrature formulas at equally spaced nodes. - J. Math. Anal. Appl., 1974, v. 47, N 2, p. 232-249.

4. Никольски й С. М. Квадратурные формулы. М., 1974.

5. С оболе в С. Л. Введение в теорию кубатурных формул. М., 1974.

6. Крылов В. И. Приближенное вычисление интегралов. М., 1967.

7. Бах в а лов Н. С. Численные методы, т. І. М., 1975.

8. Моторный В. П. О наилучшей квадратурной формуле вида $\sum_{k=1}^{n} p_{k} f\left(x_{k}\right)$ для некоторых классов периодических дифференцируемых функций. - Докл. АН СССР, 1973, т. 211, № 5, c. 1060-1062.

9. Женсык 6 а е в А. А. О наилучшей квадратурной формуле на классе $W^{r} L_{p}$. Докл. АН СССР, 1976, т. 227 , № 2, с. $277-279$.

10. Г и ршови ч Ю. Один метод построения наилучших квадратурных формул типа Маркова. - Изв. АН ЭССР, Физ. Матем., 1976, т. 25, № 2, с. 197-201.

11. Л е и н М. И., Ги рш о и ч Ю. М., А р ро В. К. О наилучших на множествах функций квадратурных формулах. - Докл. АН СССР, 1976, т. 226, № 1, c. $51-54$.

12. S a r d, A. Best approximate integration formulas, best approximation formulas. SIAM J. Numer. Anal., 1949, v. LXXI, N 1, p. 80-91.

13. Schoenberg, I. J. On monosplines of least deviation and best quadrature formulae. - SIAM J. Numer. Anal., 1965, v. 2, N 2, p. 144-170.

14. Karlin, S. Best quadrature formulas and splines. - J. Approximat. Theory, 1971, v. $4, \mathrm{~N} \mathrm{1}, \mathrm{p} .59-90$.

15. Ги ршович Ю. Оптимальные квадратурные формулы с фиксированными узлами. - Изв. АН ЭССР, Физ. Матем., 1976, т. 25, № 2, с. 201-204.

Tallinn Polytechnic
Institute

Received

June 27, 1977

\section{J. GIRSOVITS}

\section{EULER-MACLAURINI JA GREGORY TUOPI KVADRATUURVALEMITE EKSTREMAALSED OMADUSED}

Artiklis on tōestatud, et modifitseeritud Euler-Maclaurini kvadratuurvalem (3) on parim valem (9) hulgal $W^{r} L_{q}(1 \leqslant q \leqslant \infty)$ ning Gregory tüüpi kvadratuurvalem (4) on asümptootiliselt parim valem (1) hulgal $W^{r} L_{q}(1<q \leqslant \infty)$. 


\section{Ю. ГИРШОВИЧ}

\section{ЭКСТРЕМАЛЬНЫЕ СВОЙСТВА КВАДРАТУРНЫХ ФОРМУЛ ТИПА ЭИЛЕРА-МАКЛОРЕНА И ГРЕГОРИ}

Основные результаты работы:

Т е о рем а 2. Наилучшей на множестве $W^{r} L_{q}(1 \leqslant q \leqslant \infty)$ квадратурной формулой (9) с фиксированными крайними узлами $x_{0}=0, x_{n}=1$ является модифицированная формула Эйлера-Маклорена (3) с точной оценкой ошибки (7).

Т еорем а 3. Наилучшей на множестве $\bar{W} r L_{q} \quad(1 \leqslant q \leqslant \infty)$ формулой (11) c фиксированными крайними узлами $x_{0}=0, x_{n}=1$ является формула трапеций $c$ точной оценкой ошибки (7).

Т е орем а 5. Формула типа Грегори (4) является асимптотически наилучшей на множестве $W^{r} L_{q}(1<q \leqslant \infty)$ формулой (1) при $m \geqslant r-1$.

$P(x)$ и $Q(x)$ в $(4)$ суть многочлены степени $m$, интерполирующие интегрируемую функцию в точках $0,1 / n, \ldots, m / n$ и $(n-m) / n,(n-m+1) / n, \ldots, 1$ соответственно. 